\title{
Factors Contributing to Delay in Diagnosis and Start of Treatment of Leprosy: Analysis of Help-seeking Narratives from a Community Study in Dang District
}

\author{
Madhusudan Subedi \\ Ulla-Britt Engelbrektsson
}

\begin{abstract}
Prolonged delays between first symptoms and diagnosis easily result in more impairment in newly detected leprosy patients, and aggregate negative consequences for individuals and their families. In cases of infectious leprosy, longer delays increase the risk for the spread of the disease. Limited studies have been carried out to explore the causes for delays in Nepal. This is a community level qualitative study conducted in Dang district. The information was obtained through in-depth interviews with 8 leprosy affected persons, 8 contacts, 8 community members and 5 service providers in Dang district. Skin patches were regarded as a simple skin disease, in particular of paucibacillary patients who had a limited number of skin lesions and no nerve damage. A local medical shop was the first choice for medicine to treat skin conditions. Delays in diagnosis of leprosy occurred at many stages from the development of the symptoms to consultation of health care services. The use of traditional medicine, a belief in self-cure and visit to traditional healers, and misdiagnosis (a disease other than leprosy by the health worker) and inadequate knowledge about the disease and its early symptoms were the main factors that influenced the delayed diagnosis. Delays accumulated as the result of series of help-seeking actions that reflected local socio-cultural beliefs and practices. Misdiagnoses could be reduced if adequate information on leprosy is given to community people and health service providers. Specific interventions are needed to promote knowledge and a good attitude among contacts and community members. To reduce patient delay, public health promotion is needed to increase the awareness of leprosy, and the health service delay should be reduced by improving diagnostic skills in public and private sectors. Addressing both components of delays will decrease the time to diagnosis and ultimately the extent of transmission of the disease and reduce the risk of nerve function impairments.
\end{abstract}

Keywords: leprosy, patient delay, health service delay, misdiagnosis, Nepal

\section{Introduction}

Leprosy is one of the Neglected Tropical Diseases and a leading cause of preventable disability worldwide (Henry et al., 2016). Despite the elimination of leprosy as a public health problem globally in 2000 and at the national level in most countries by 2005, leprosy cases continue to occur. Over 200,000 new leprosy cases were reported in 2016 (WHO, 2017). Therefore, guidance on early detection and immediate initiation of treatment are essential for an effective leprosy control program (Rojas et al., 1994, Engelbrektsson 2012) and prevent severe disability. Delay in diagnosis for leprosy affected persons is usually defined as the duration of time from onset of symptoms to the initiation of medical treatment. It includes patient delay from onset of symptoms to the first interaction with health services, and system delay from the first visit to health services to initiation of treatment. In this context, delay means the time span between become aware of leprosyrelated symptoms and start of appropriate drug treatment, MDT.

Delay in diagnosis is significant to both disease prognosis at the individual level and transmission within the community (Lockwood and Reid, 2001). We searched the literature for leprosy delays in Nepal but found that only few studies (Robertson et al. 2000, Choulagain et al. 2005) have been done. These studies had not focused on the socio-cultural aspects of delays. We therefore conducted this study with the aim of exploring socio-cultural factors that contribute to overall delay in diagnosis and treatment of leprosy. Being a qualitative study, we have highlighted help-seeking narratives of the leprosy affected persons, contacts, community members and health workers for exploring the factors contributing to delay.

Leprosy is a chronic infectious disease caused by Mycobacterium leprae, an acid fast, rod shaped bacillus (Lockwood and Suneetha, 2005). The incubation period for leprosy is about five years before symptoms and signs of leprosy develop. Because of the long incubation period, infection with Mycobacterium leprae may not be observed or experienced by the affected persons in its early stages. This uniqueness can lead to misdiagnosis and consequently to long-term morbidity and disfigurement (Choulagai et al. 2005). It mainly affects the skin, peripheral nerves, and 
mucosa of the respiratory tract. Multidrug therapy (MDT) treatment has reduced the transmission of leprosy so effectively (Engelbrektsson, 2012) that the disease is rarely seen in higher income countries.

On the basis of clinical manifestations and skin smear results, leprosy is classified into two categories. Patients showing negative smears at all sites are grouped as paucibacillary leprosy ( $\mathrm{PB})$, while those showing positive smears at any sites are grouped as having multibacillary leprosy (MB). While classifying leprosy, it is particularly important to ensure that patients with $\mathrm{MB}$ cases are not treated with the regimen for the $\mathrm{PB}$ form of the disease (WHO, 2012).

Early detection of leprosy is critical to leprosy control and elimination. A great variety of factors contribute to early or late presentation, and in any given community some reasons for delays are more common or more importance than others (Choulagai et al. 2005; Nicholls et al. 2006). Long delays aggregate negative consequences for individuals and their families, and in cases of infectious leprosy increase the risk for the spread of the disease (Robertson et al., 2000). Thus, shortened delays are essential to reach the goals of minimizing negative effects of the disease for those affected and their surroundings and to attain the ultimate goal of national eradication. To accomplish shorter delays present patterns have to be investigated and key barriers identified and addressed (Subedi 2018). Thus, the main objective of this study was to discover socio-cultural barriers and the length of inaction in a cluster of Dang district which we call Sisagaon, the west Tarai of Nepal.

\section{Methods, Materials and Study Limitations}

This is a community level qualitative study conducted in Dang district. The study area was selected on the basis of leprosy endemic area reported by the District Public Health Office (DPHO). The records of leprosy affected persons were taken from DPHO and verified from the Health Post (HP) in Sisagaon. Contact details of the leprosy affected persons were taken from the HP. The information was collected in May-June 2016.

Based on the information of 17 leprosy affected persons who had taken medicine from the HP, the first author of this article conducted community study. Some of the affected persons had permanently migrated to other places and some had gone to India for work. The purpose of the study was clearly communicated to the affected persons and their family members, community people and the health workers. All the study participants were assured that the information would be confidential. They were also told their experiences and knowledge would be pertinent for the better understanding of the disease and would be helpful for the policy makers and planners who have been working in leprosy eradication programs.

Initially, the affected persons and their family members were not comfortable to share the information. However, after the sharing the importance of the research and the value of their experiences for the betterment of others, they felt comfortable and agreed for the interview. Based on their preferences, interview date, time and venue were decided.

The information was obtained through in-depth interviews with 8 leprosy affected persons, 8 contacts (household members), 8 community members (never being affected by leprosy but living in the same community) and 5 service providers. With the help of semi-structured study tools, interviews were conducted to obtain individual perceptions and experiences. To establish an in-depth conversation, participant's responses were extensively probed to explore delayed health seeking and start of treatment.

Interviews were conducted based on their preference - in their home, at the tea shop, in the health facility and under the tree. The health workers were interviewed either in their office or at the medical store. The qualitative data were transcribed and translated into English. The data analysis was done by creating themes and sub-themes based on the standard data collection tools. Quotes have been selected to illustrate the themes.

The ethical approval for this study was taken from Nepal Health Research Council (Ref. No. 1940/2015), an apex body of Ministry of Health, Nepal. The consent form was prepared in English, translated into Nepali language and approved by NHRC. Informed consent was taken before conducting individual interviews with the index cases, contacts, health workers and community members. Statements and opinions of the participants were handled with confidentiality and respect. No incentives or any form of reimbursements were paid.

There are some limitations in this study. This is a qualitative study which allowed the researchers to deeply explore the delay in diagnosis and treatment of leprosy. The small number of study participants may limit the extent to which the findings of this study can be generalized across the Nepal. Delays and associated factors in diagnosis of leprosy cannot be compared directly to the findings of other communities due to difference in study population and due to socio-cultural conditions. Since the study participants were purposively selected, there might have been selection bias of the study participants. Further, due to small sample size, the variables like caste and ethnic, gender, education, occupation and age, and the perception and knowledge of the individual are not compared. However, the study finding is expected equally valid for the similar sociocultural context of Nepal.

\section{Findings and Discussions}

In this paper we have divided delay into two types: patient delay and health system delay. Patient delay is the time between symptom detected and patient consulting a health worker. The health system delay is a delay between consulting a health worker and receiving a diagnosis of leprosy. 


\section{Leprosy Control Program in Nepal}

In Nepal, the vertical Leprosy Control Project was established in 1966 (Butlin 2003). At that time there were few specialized human resources working in government service. However, several non-governmental organizations were already assisting the government to diagnose and treat the leprosy affected persons and support the government to implement the leprosy elimination program. The Leprosy Control Project was integrated in its Basic Health Services in 1987 (Butlin 2003). The government of Nepal declared the elimination of leprosy on $19^{\text {th }}$ January $2010^{1}$.

Leprosy care is integrated into primary care in Nepal. Medicine is provided to leprosy affected persons from all the public health facilities. At least one health worker from each public health facility has undergone Comprehensive Leprosy Training in leprosy endemic districts and a majority of them have an additional Refresher Leprosy Training as well (Jain, 2008). These health facilities are expected to carry out leprosy diagnosis and treatment services, patient counseling, contact examination, community health education, focal case detection drives, treatment of minor complications and referral services.

There is a Leprosy Control Division (LCD) $)^{2}$ located at the center headed by a Director, mainly responsible for laying down the policy, deciding on the strategy of leprosy control and issuing periodically updated national guidelines for leprosy control activities in the country. The leprosy control program is supported by several international and national non-governmental organizations. leprosy. Table 1 clearly depicts that irrespective of age, caste/ethnicity and occupation people can be affected by leprosy.

Leprosy affected persons were asked to share their perceived causes of disease. The respondents did not tell on the disease as such but shared their own experiences. There was a great variation among the respondents regarding the general insights into leprosy.

I thought it was a simple mark. I did not care so much. After few months there was a swelling spot in my left hand, I became worried. P1M1.

I did not even think that it was [leprosy]. I thought it was a skin disease. For skin disease we do not take it seriously. I waited few months before consulting the medical store. P2M2

I was feeling weak at that time. I thought that it was due to hard work. I did not see any visible sign and symptoms. One day, my neighbor showed me skin patch when we were washing clothes in public tap but I did not care her words. After six months, it formed anesthetic skin lesion. P8F4

I was not aware about the disease and did not have idea either. I did not have pain. I was able to do regular work as usual. I did not take the sign and symptoms seriously. P6F2

The understanding of bodily affliction when people feel unwell, or when they experience any sudden unexpected

Table 1: Socio-economic Characteristics of Leprosy Affected Persons

\begin{tabular}{|l|l|l|l|l|l|l|l|}
\hline Respondent & Sex & Age & $\begin{array}{l}\text { Caste/ } \\
\text { Ethnicity }\end{array}$ & Education & Occupation & PB/MB & $\begin{array}{l}\text { Time }(\text { in } \\
\text { months }\end{array}$ \\
\hline P1M1 & Male & 53 & Chhetri & Class 8 & Farm work & MB & 36 \\
\hline P2M2 & Male & 68 & Tharu & Illiterate & Farm work & MB & 40 \\
\hline P3M3 & Male & 19 & Brahmin & Class 11 & Student & PB & 6 \\
\hline P4M4 & Male & 32 & Tharu & Bachelor & Wage labourer & PB & 18 \\
\hline P5F1 & Female & 28 & Brahmin & Class 10 & Housewife & PB & 15 \\
\hline P6F2 & Female & 49 & Dalit & Class 9 & Housewife & MB & 24 \\
\hline P7F3 & Female & 24 & Tharu & Class 12 & Small business & MB & 40 \\
\hline P8F4 & Female & 45 & Brahmin & Class 7 & Housewife & PB & 20 \\
\hline
\end{tabular}

Source: Field Study, $2016 *$ Start of multi-drug therapy (MDT) treatment before the study.

These organizations, however, have focused mainly on the curative aspects.

\section{Patient Delay: Help-seeking Behavior of Leprosy Affected Person and Misdiagnoses}

All the study participants mentioned that it took more than six months to start the appropriate medicine to treat

1. Elimination of leprosy is defined by the World Health Organization as being achieved when there are fewer than one in 10,000 people on anti-leprosy treatment.

2. The government of Nepal has not provided clear organogram of the different divisions and its related activity after the state restructuring in 2015. events are linked with the culturally constructed reality. The realities are linked with socio-economic organizations and patterned worldviews (Kleinman, 1980). Thus, the participants who thought that the symptoms were not the serious had longer delays.

The participants were asked the number of months spent before consulting the health worker who were working in the government health facility or private hospital. The average delay is diagnosis of leprosy was 15 months. All the leprosy affected persons practiced self-medication immediately after the onset of symptoms. They had relied on the home remedies. Using oil massage, administrating herbs and barks, and follow the recommended dietary restriction and prescriptions were the major household- 
based self-medication practices.

My mother suggested me for oil massage and I did as per the suggestion for 2 months but the patch expanded day by day. P1M1

I was not allowed to eat meat for 3 months. Likewise, some vegetables were restricted to eat. P5F1

I was suggested to make a paste of leaf of special beans and put on the lesions for more than 15 days. For some time, I thought it worked but it did not work and I was feeling weak. P6F2

My father suggested me to apply betel nut paste on my swelling spot. I did it for more than a month. P8F4.

Thus, one of the main causes of delay was householdbased self-medication. The family members had thought that the various types of skins diseases would heal from household medication. The family members did not even think that a small patch could be the sign and symptom of leprosy.

The leprosy affected persons, while exploring further their health seeking behavior, mentioned that they had visited temples for worshiping gods and goddesses and had offered sweets and flowers.

The medical halls were available within the village or nearby. Visits to the medical hall were very common. All the study participants had visited medical hall at least once for their treatment. Some had visited three to five times and even more.

I did different treatments in the local medical shop. He same medical hall and complained. He gave me medicine and said that it would work. But it was not cured. P6F2.

Beine (2012) says that many patients in Nepal depend on medical halls and that the consequences are delays in seeking treatment from qualified practitioners. This has led to some medical "train wrecks" among the patients who arrive later at the hospital. This phenomenon is negatively impacting health care in Nepal.

Out of 8 leprosy affected persons, 6 had visited traditional healers. The traditional healers had gone into trance by inquiring about and observing physical symptoms. The affected persons were treated by chanting mantras and shouting at the spirits to leave the person's body, and by giving offering and doing sacrifices.

I had one patch. I visited to Dhami. P5F1

Dhami told that something is wrong, so we did some pooja [worship] for correction in our house. P1M1

The key risk factors for patient delay were inadequate knowledge regarding the disease and seeking health care from non-specialized individual at onset of symptoms such as Dhami-Jhanrki, Janne manchhe, fukne manchhe and medical store.

All the leprosy affected persons reported a delay of several months, sometimes a year or more, between onset of the symptoms and initiation of leprosy treatment. For several leprosy patients, appropriate treatment was delayed because they believed that they were suffering from something other than leprosy. Prolonged self-medication also delayed correct treatment.

The findings show that it is important to involve people

Table 2: Background information of contacts of leprosy affected persons

\begin{tabular}{|l|l|l|l|l|l|l|}
\hline Respondent & Sex & Age & Caste/Ethnicity & Education & Occupation & $\begin{array}{l}\text { Relation to affected } \\
\text { person }\end{array}$ \\
\hline C1F1 & Female & 50 & Chhetri & Illiterate & Farm work & Husband \\
\hline C2F2 & Female & 60 & Tharu & Illiterate & Farm work & Husband \\
\hline C3F3 & Female & 40 & Brahmin & Class 10 & Housewife & Father \\
\hline C4F4 & Female & 55 & Tharu & Illiterate & Wage labourer & Father \\
\hline C5M1 & Male & 32 & Brahmin & Intermediate & Teacher & Wife \\
\hline C6M2 & Male & 55 & Dalit & Illiterate & Wage Labourer & Wife \\
\hline C7M3 & Male & 24 & Tharu & Class 8 & Small business & Sister \\
\hline C8M4 & Male & 22 & Brahmin & Intermediate & Farm work & Sister \\
\hline
\end{tabular}

Source: Field study, 2016

gave me 5-7 packets of medicine for the patches but it was not worth it. My hands used to get swollen and pumped up. P1M1.

I was taken to private clinic. My father told to the health worker about the patches. I was given different types of medicine but did not work. P4M4.

I visited the medical hall which is only 10 minutes walking distance from my home. At first, the person said it was ringworm. So, I thought its ringworm. And then I took medicine of ringworm and applied antiseptic in the patches. When it did not work, I again visited to the in early medical examination by explaining that leprosy can easily be cured if they pursue medical care in time. It is possible for the leprosy affected persons to avoid passive behavior if the patient knows what and how to manage the situation with early symptoms.

Misdiagnosis by the private practitioners was the main factor that influenced the delayed diagnosis. Other factors were: use of traditional medicine, self-cure and influence of traditional healers. A few participants mentioned that they were incorrectly diagnosed at their first place of consultation in the government health facility (Sub Health Post and Health Post), which caused further delay. 


\section{Contact: Perceptions and Seeking Behavior and Misdiagnoses}

A total of 8 contacts were covered in the study, comprising 4 males and 4 females. The contacts were the household members.

When asked about sign and symptoms of leprosy, some respondents could not say anything on the subject whereas others had some ideas. Since 'the contacts' were close family member of the leprosy affected persons who had already gone for appropriate treatment, most of them had clear ideas about what caused the delay in diagnosis. The contacts had received the information of leprosy from the health worker. Individual carelessness was among the most cited causes for delay.

Unlike other diseases, leprosy affected persons commonly at an early stage do not have severe pain or very dangerous sign and symptoms.

They get skin patches and do not care for some time. In my opinion, this is the main cause of delay in diagnosis in leprosy. C5M1.

People do not take it seriously when initial sign and symptoms occur. C3F3.

The contacts mentioned that the trust in traditional healer or janne manchhe and fukne manchhe are other causes of delays in diagnosis.

People say this disease happens due to the bad deeds that we have done in the past life, curse from the gods and only the traditional healer can cure it. Since we are living of other skin diseases. They give unnecessary medicine. This is a harmful practice. C3F3.

Private practitioners do not diagnose the disease properly but give unnecessary medicine. They do not have adequate medical training. C5M1

\section{The Community Members: Social Characteristics, knowledge and community perceptions}

As stated earlier, a total of 8 community members were covered in the study, comprising 5 males and 3 females. Community members were asked to tell about the leprosy, its causes and symptoms. Some community members had a good knowledge about leprosy its cause and symptoms and while other had only partial knowledge, and some had misconceptions.

People say while itching, it is senseless. It's numb and senseless. It does not pain. R1M1.

Leprosy is caused by special kind of bacteria. It is like other diseases. It is a curable disease if diagnosed in time and treated as per the suggestion provided by the medical doctors. R2M2.

I do not know about the leprosy and its causes. R5M5.

The community members stated that the trust in householdbased medicines, use of herbal medicines, roots and barks of some medicinal plants, avoidance and preferences of specific food are major causes of delay in diagnosis.

The community members further mentioned that the over trust to local medical hall is another cause of delay. The operators of local medical halls do not have adequate knowledge about the

Table 3: Background information of the community members

\begin{tabular}{|l|l|l|l|l|l|}
\hline Respondent & Sex & Age & Caste/Ethnicity & Education & Occupation \\
\hline R1M1 & Male & 65 & Brahmin & Class 10 & Business \\
\hline R2M2 & Male & 40 & Tharu & Bachelor & Teacher \\
\hline R3M3 & Male & 45 & Chhetri & Bachelor & Social Worker \\
\hline R4M4 & Male & 55 & Brahmin & Intermediate & Business \\
\hline R5M5 & Male & 50 & Tharu & Class 10 & Business \\
\hline R6F1 & Female & 40 & Brahmin & Illiterate & Social Worker \\
\hline R7F2 & Female & 36 & Tharu & Intermediate & Health Worker \\
\hline R8F3 & Female & 30 & Chhetri & Intermediate & Housewife \\
\hline
\end{tabular}

in the village, we have to trust the suggestions provided by the relatives and neighbors. $\mathrm{C} 2 \mathrm{~F} 2$.

Some contacts mentioned that the public health facility is far from the village and the health workers are not available. On the other hand, private medical halls are easily available in the village or nearby. The contacts mentioned that the leprosy affected persons were taken to the medical hall but their disease was not cured. The contacts had clear impression that the persons who run the medical hall do not have adequate knowledge to diagnose leprosy in its early phase.

The private practitioners do not have adequate knowledge on leprosy and its sign and symptoms. They give medicine sign and symptoms of disease like leprosy. They further stated that the private medical clinic prescribe unnecessary antibiotics.

\section{Health Workers: Information about Leprosy, Training and Community Perceptions}

Health workers stated that the leprosy affected persons do not visit the health facility when they get initial sign and symptoms of the leprosy.

The main symptom of leprosy is senseless patch(s). If you touch the spot there is no feeling of sense. People do not take it seriously. HW1

No itching and no pain in body's patches. Dry kinds of patches are seen visible. HW2. 
Some people still think and call it a curse from God, results of the sins done in our former or past life, etc. HW3.

Trust to local dhami-jhankri is another cause of delay. HW4.

All the health workers stated that people still trust in traditional healers and faith-based activities. They also mentioned that the trust in traditional healers has decreased compared to past.

In response to the training related to leprosy diagnosis and treatment, most of the health workers mentioned that they had received training at least one time in their professional work.

I have not yet get any training, what I learn about leprosy was during my academic course. I have no specific training. HW3.

Long time ago in Nepalganj and between my works but I don't remember the exact date. HW2.

The health workers admitted that it is difficult to diagnose leprosy affected persons compared to other diseases like tuberculosis, hypertension, diabetics etc.

\section{Conclusion}

In general three types of people were found in the study area. People who were providing services and who were adequately or partly aware about the nature of the disease and modes of transmission, people with little or no knowledge of leprosy and the free services available for the diagnosis and treatment at government health facility, and those who are helping the stigmatized and advocating about the need and importance of early diagnosis and treatment. At the community level, most of the people did not have knowledge about the nature of the disease and mode of transmission. Although social stigma and discrimination is less than in the past affected persons has reduced compared to past but affected persons are still stigmatized and discriminated. Skin patches were regarded as a simple skin disease, in particular of PB patients who had a limited number of skin lesions and no nerve damage. Both socio-cultural and health system related factors were associated with longer diagnostic delays. A long period of initial inactivity was found because early symptoms were not recognized as sign of serious condition. The initial inactivity was followed by help-seeking activity within the popular sector of health care, household-based selfmedication and use of locally available herbal medicine. Visit to local janne manchhe and fukne manchhe, and worship and sacrifice to various Gods and Goddesses are still prevalent.

Within the bio-medical sphere, the private sector was the first choice for most of the leprosy affected persons. Many private medical halls were easily available in the village or nearby. However, they did not have adequate knowledge on diagnosis of leprosy. Misdiagnosis by private practitioners and health workers in public health facilities, followed by social stigma and underestimation of the problem in the initial phase of sign and symptoms were the key. The findings clearly depict the importance of informal and private sector engagement to shorten the case-seeking pathway. Misdiagnoses could be reduced if adequate information is given to private practitioners. Specific interventions are needed to promote knowledge and a good attitude among contacts and community members. To reduce patient delay, public health promotion is needed to increase the awareness of leprosy, and the health service delay should be reduced by improving diagnostic skills in public and private sectors. Addressing both components of delays will decrease the time to diagnosis and ultimately the extent of transmission of the disease and reduce the risk of nerve function impairments.

\section{Acknowledgements:}

This paper is the outcome of a research project, 'Delays in Diagnosis and Treatment, Leprosy in Nepal' carried out by the International Nepal Fellowship, Nepal, and financially supported by the Leprosy Research Initiative, the Netherlands. The paper was presented in an International Conference organized by Nepal Sociological Association on 21-22 November 2017 in Pokhara. We would like to acknowledge the feedback provided by the reviewers and the editors of the journal.

\section{References}

Butlin, C. R. (2003). Nepal network of Leprosy NGOs. Leprosy Review, 74:163-166.

Beine, D. (2012). The Medical Hall: The New Shamans? Examining a New Trend and Its Implications in Health Seeking Behavior in Nepal. In Dilli Ram Dahal, Laya Prasad Uprety and Bipin Kumar Acharya eds. Readings in Anthropology and Sociology of Nepal (Pp 2-19). Kathmandu: Sociological / Anthropological Society of Nepal.

Choulagai B; Onta, S.; Bhattarai, P. (2005). Patient Delay in Leprosy Treatment in Jhapa District Nepal. Journal of Nepal Health Research Council, 3: 29-34

Engelbrektsson, U. (2012). Challenged Lives: A Medical Anthropological Study of Leprosy in Nepal. Gothenburg: University of Gothenburg.

Henry, M.; GalAn, N., Teasdale, K.; Prado, R.; Amar, H.; Rays M.S., Roberts, L; Siqueira, P.; Wildt, G.; Virmond, M. and Das, P.K. (2016). Factors Contributing to the Delay in Diagnosis and Continued Transmission of Leprosy in Brazil - An Explorative, Quantitative, Questionnaire Based Study. PLoS Negl Trop Dis 10(3): e0004542. doi:10.1371/journal. pntd.0004542

Jain, M.C. (2008). Leprosy Scenario of Nepal. Journal of Nepal Medical Association, 47(172):259-63.

Kleinman, A. (1980). Patients and Healers in the Context of Culture: An Exploration of the Borderland between Anthropology, Medicine, and Psychiatry. Berkeley: University of California Press.

Lockwood, D.N. J. and Suneetha, S. (2005). Leprosy: Too Complex a Disease for a Simple Elimination

Paradigm. Bulletin of the World Health Organization, 83 (3): $230-235$. 
Lockwood, D.N. J. and Reid, A.J.C. (2001). The Diagnosis of Leprosy is Delayed in the United

Kingdom. Quarterly Journal of Medicine, 94:207-212.

Nicholls, P.G.; Ross, L. and Smith, W.C.S. (2006). Promoting in Early Detection in Leprosy: A Literature

Review to identify proven and potential Interventions Addressing Patient-related Delay. Leprosy Review, 298-310.

Rojas, V.D., Hernandez, O. and Gil, R. (1994). Some Factors Influencing Delay in Leprosy Diagnosis.

Bulletin of PAHO, 28(2): 156-162.

Robertson, L.M.; Nicholls, P.G. and Butlin, R. (2000). Delay in Presentation and Start of Treatment in Leprosy: Experience in an Out-patient Clinic in Nepal. Leprosy Review, 71: 511-516.

Subedi, M. (2018). State, Society and Health in Nepal. New Delhi: Routledge.

Subedi, M. (2001). Medical Anthropology of Nepal.

Kathmandu: Uday Books.

WHO (2017). Guidelines for the Diagnosis, Treatment and Prevention of Leprosy. Geneva: WHO.

WHO (2012). WHO Expert Committee on Leprosy. Geneva: WHO.

Subedi, Madhusudan is Professor in School of Public Health, Patan Academy of Health Sciences, and Central Department of Sociology, Tribhuvan University, Nepal. Subedi's writtings are focused on 'social determinants of health', 'women and health', 'pharmaceuticals', 'infectious diseases', 'disability', 'caste system', 'informal networking', 'qualitative research methods' and 'polity and social transformation' in Nepal.

Email:madhusudansubedi@gmail.com

Engelbrektsson, Ulla-Britt ( $\mathrm{PhD}$ in Social Anthropology, 1979) was Associate Professor(1998-2009) at the University of Gothenburg, Sweden, and between 2010-2014, she served as a member of the University of Gothenburg's Global University Initiative. Engelbrektsson's publications within medical anthropology are focused on socio-cultural aspects of infectious diseases especially Tuberculosis and Leprosy. Currently, she is associated to the Shining Hospital INF Surkhet, Nepal.

Email: ulla-britt.engelbrektsson@inf.org 